\title{
Specular Microscopy
}

National Cancer Institute

\section{Source}

National Cancer Institute. Specular Microscopy. NCI Thesaurus. Code C120542.

A noninvasive photographic technique used to visualize and examine the corneal

endothelium, in which a source of light is projected onto the cornea and the subsequent

image reflected from the optical interface between the corneal endothelium and the aqueous humor is captured. 